
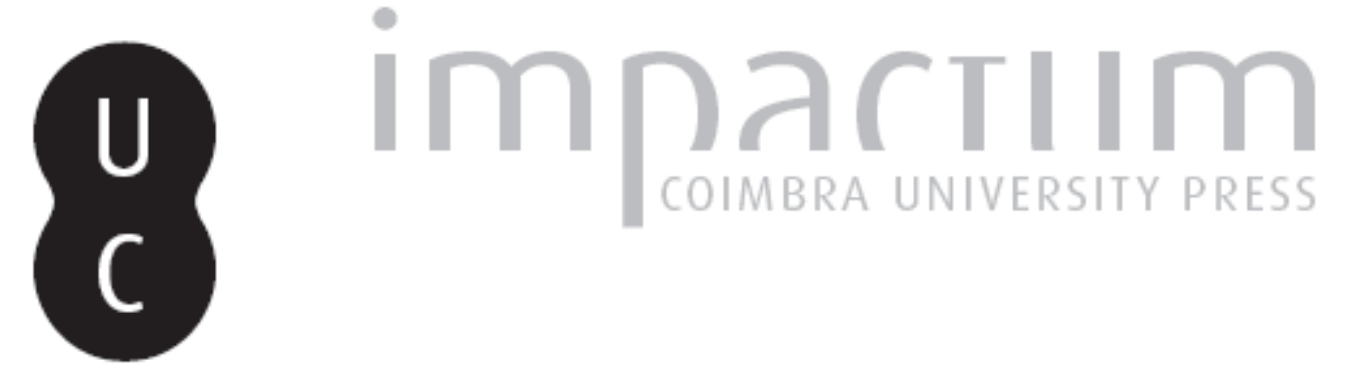

\title{
A emissão de moeda de ouro de Gallienus no início do reinado conjunto com Valerianus I: notas a propósito de um medalhão monetário de Tongobriga
}

Autor(es): $\quad$ Centeno, Rui M. S.

Publicado por: Faculdade de Letras da Universidade de Coimbra

URL persistente:

URI:http://hdl.handle.net/10316.2/38800

DOI:

DOI:http://dx.doi.org/10.14195/1647-8657_53_6

Accessed : $\quad$ 26-Apr-2023 14:38:54

A navegação consulta e descarregamento dos títulos inseridos nas Bibliotecas Digitais UC Digitalis, UC Pombalina e UC Impactum, pressupõem a aceitação plena e sem reservas dos Termos e Condições de Uso destas Bibliotecas Digitais, disponíveis em https://digitalis.uc.pt/pt-pt/termos.

Conforme exposto nos referidos Termos e Condições de Uso, o descarregamento de títulos de acesso restrito requer uma licença válida de autorização devendo o utilizador aceder ao(s) documento(s) a partir de um endereço de IP da instituição detentora da supramencionada licença.

Ao utilizador é apenas permitido o descarregamento para uso pessoal, pelo que o emprego do(s) título(s) descarregado(s) para outro fim, designadamente comercial, carece de autorização do respetivo autor ou editor da obra.

Na medida em que todas as obras da UC Digitalis se encontram protegidas pelo Código do Direito de Autor e Direitos Conexos e demais legislação aplicável, toda a cópia, parcial ou total, deste documento, nos casos em que é legalmente admitida, deverá conter ou fazer-se acompanhar por este aviso.

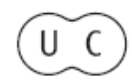


CONIMBRIGA

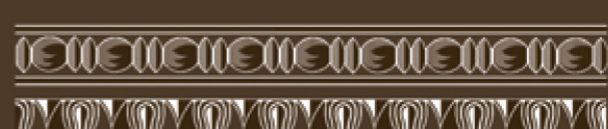

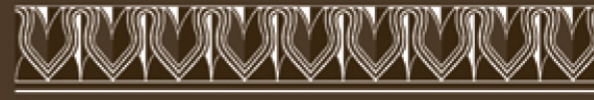

INSTITUTO DE ARQUEOLOGIA

VOLUME LIII • 2014

FACULDADE DE LETRAS 
Rui M. S. CENTENO

Universidade do Porto, Faculdade de Letras e CITCEM

rcenteno@letras.up.pt

A EMISSÃO DE MOEDA DE OURO DE GALLIENUS NO INÍCIO DO REINADO CONJUNTO COM VALERIANUS I: NOTAS A PROPÓSITO DE UM MEDALHÃO MONETÁRIO DE TONGOBRIGA

GOLD COINAGE OF GALLIENUS IN THE BEGINNING OF THE JOINT REIGN WITH VALERIANUS I: NOTES ON A MONETARY MEDALLION FOUND IN TONGOBRIGA

"Conimbriga" LIII (2014) p. 177-199

http://dx.doi.org/10.14195/1647-8657 53_6

Resumo: Estuda-se um pendente de ouro com um aureus de Gallienus, datado do início do reinado conjunto (253-54), encontrado na zona das termas do povoado romano de Tongobriga (Marco de Canaveses, Porto), contextualizando-se esta peça de ourivesaria com outras procedentes da parte ocidental do Império Romano. É também apresentada uma lista ordenada das ligações de cunhos de 26 aurei pertencentes a coleções públicas e privadas que permite um melhor conhecimento da cunhagem de moeda de ouro no início do reinado conjunto de Gallienus. Por último, discute-se o contexto arqueológico em que foi perdido o medalhão de Tongobriga e que deverá situar-se em meados do século IV.

PALAVRAS-CHAVE: medalhão monetário romano; pendente de ouro; aurei de Gallienus (reinado conjunto); Tongobriga

ABSTRACT: It is studied a gold pendant with a Gallienus aureus, dated of the beginning of the joint reign (A.D. 253-54) and found in the area of the roman baths of Tongobriga (Marco de Canaveses, Porto).

Conimbriga, 53 (2014) 177-199 
This medallion is related to others similar pieces coming from the western part of the Roman Empire. It also published a list of die links detected in a set of 26 aurei from public and private collections, that allows a better understanding of the gold coinage at the beginning of the joint reign of Gallienus. Finally, it discusses the archaeological context in which it was lost Tongobriga medallion presumably in the mid-fourth century.

KEYWORDS: roman monetary medallion; gold pendant; aurei of Gallienus (joint reign); Tongobriga 


\section{A EMISSÃO DE MOEDA DE OURO DE GALLIENUS NO INÍCIO DO REINADO CONJUNTO COM VALERIANUS I: NOTAS A PROPÓSITO DE UM MEDALHÃO MONETÁRIO DE TONGOBRIGA}

A excecional peça que agora se publica, foi encontrada no decurso da campanha de trabalhos arqueológicos de 1984 no sítio romano do Freixo (Marco de Canaveses, Porto) (FIG.1), sob a direcção de Lino Tavares Dias, a quem devemos a primeira notícia do achado e a respectiva contextualização estratigráfica. ${ }^{1}$

O medalhão monetário ${ }^{2}$ apresenta as características seguintes:

- O aureus (Figs. 2-3)

Anv.) IMP CP LIC GALLIENVS AVG

Busto laureado de Gallienus à direita, barbado e com couraça, vista de frente.

Rev.) IOVI CON-SERVA

Júpiter de pé, de frente, com a cabeça à esquerda, manto caído sobre o ombro esquerdo, segurando o raio na mão direita e o cetro vertical na esquerda

Casa da moeda: Roma

${ }^{1}$ Dias 1997: 58, Estrato 7. Este trabalho constituiu a sua dissertação de doutoramento apresentada na Faculdade de Letras da Universidade do Porto em 1995.

Expressamos aqui o nosso agradecimento ao Doutor Lino Tavares Dias pela disponibilização desta peça para estudo.

${ }^{2}$ A designação destes objectos de adorno não é consensual na bibliografia da especialidade. Por exemplo, na ourivesaria tradicional vianense, os objectos constituídos por moedas engastadas em molduras são designados por "peças", reservando-se a palavra "medalha" para os pendentes que imitam moedas (cf., v.g., ABREU 2006: 76 e 78 e Costa \& Freitas 2011: 153-56).

Conimbriga, 53 (2014) 177-199 
Cronologia: agosto 253-agosto 254 (MIR 36: 76, ROM1)

Peso: 4,48 g (moeda: 2,99 g; moldura: 1,49 g)

Diâmetro: 18,9 mm (moeda); 23,7 mm (moldura), 27,0 mm (moldura com argola)

Orientação dos cunhos: $7 \mathrm{H}$

Referência: RIC V/1, 76(E); MIR 36, 25p

- A guarnição (Figs. 4-5)

Aureus de Gallienus montado numa moldura composta por um estreito aro circular de ouro (cerca de $2 \mathrm{~mm}$ ), decorado a cinzel no anverso com a repetição de um motivo triangular que se poderá identificar com folhas muito estilizadas; no perímetro interno deste aro foi soldada uma lâmina de ouro, com uma secção em forma de $\pi$, para a fixação da moeda; uma argola para suspensão, rematada de cada lado com um pequeno rebordo, encontra-se soldada à guarnição; a moldura apresenta-se partida imediatamente à esquerda da soldadura da argola. A baixa qualidade da guarnição revela que foi executada por artífice pouco habilidoso, talvez um ourives local ou da região, sem "arte" para realizar um trabalho mais delicado, como seria o modelo que the serviu de inspiração.

O tipo de moldura enquadra-se nos medalhões do grupo 1 (decoração tipo 1), proposto por Brenot e Metzger (1992: 345-46), onde são utilizados, geralmente, numismas dos imperadores das dinastias dos antoninos ou dos severos mas também moedas mais recentes até à década de setenta do século III. Para o motivo decorativo utilizado na guarnição são conhecidos diversos paralelos muito próximos da peça agora estudada mas geralmente com uma arte mais elaborada: a título exemplificativo, do século II, pode-se referir uma peça de colar ${ }^{4}$ com um aureus de Faustina II (sob Antoninus Pius) (RIC III, 511), pertencente ao tesouro de Beaurains (BASTIEN \& MetZGer 1977: 179, n. ${ }^{\circ} 3$ e Est. IX, 3); ${ }^{5}$ já da centúria seguinte temos o colar de ouro com um

${ }^{3}$ A data de 254-5, avançada em RIC V/1 para esta emissão, é menos seguida do que a proposta por Göbl 1951: 19-20, $2^{\mathrm{a}}$ emissão, fim de 253-Primavera de 254, recentemente atualizada, em MIR 36/43/44: 76.

${ }^{4}$ Por se tratar de um elemento de colar articulado e não um medalhão para suspensão, apresenta duas argolas laterais.

${ }^{5}$ Para outras peças da parte ocidental do Império com molduras idênticas guarnecendo aurei dos imperadores antoninos, cf. BRENOT \& METzGer 1992: Est. I, 32, 33, 
aureus de Severus Alexander (BMCRE VI, 128), da antiga coleção Castellani, hoje no Museu Britânico (Marshall 1911: 316, n. ${ }^{\circ} 2727$ e Est. LIX, 2727), bem como o pendente com aureus de Gallienus, já como único imperador (RIC V/1, 53; MIR 36/43/44, 4091), datável do ano 261 (GöBL 1953: 13), também pertencente ao referido museu (MARSHALL 1911: 349-50, no. 2939 e Est. LXVIII, 2939).

Uma variante mais elegante e cuidada deste motivo decorativo da guarnição, apresenta o aro com as folhas vazadas, documentada em medalhões da dinastia antonina e também do século III, como o exemplar da antiga coleção E. Durand, pertencente ao Museu do Louvre (Inv. Bj 759), com um aureus de Elagabalus (RIC IV/2, 61) (FIG. 6), ou a peça encontrada numa necrópole romana de Milão (Perassi, C. 2003) com um raríssimo aureus de Saloninus Caesar (RIC V/1, 17; MIR 36, 267a), datável entre o outono 258 e o final de 259 (GöBL 1951: 24-5, $9^{\text {a }}$ emissão), mostrando que as duas variantes de guarnição para medalhões tiveram um período de produção idêntico.

Durante uma boa parte do século III, a considerável quantidade de numismas utilizados na confecção de joias ou perfurados para suspender com fio, bem como o entesouramento de moeda nova neste metal precioso, ${ }^{6}$ contribuíram para uma significativa imobilização de numerário de ouro que praticamente deixou de circular, sendo utilizado cada vez menos como meio de pagamento (sobre esta questão, veja-se: CAllu 1969: 428-30; Hiernard 1979: 39-41; CALlu \& Loriot 1990: 106; Bland 1996: 64-6; para a Península Ibérica, SAgredo SAN EustaQui 1986: 98-99). Pelo contrário, o uso da moeda de ouro como ornamento pessoal, seja furada ou integrada em jóias, transformou-se numa moda de prestígio ao longo do século III, que terá atingido o auge

$35 \mathrm{e}, 37 \mathrm{a}$ e $37 \mathrm{~b}$; para o oriente romano, refiram-se os oito medalhões com aurei de Trebonianus Gallus (2), Volusianus (5) e Gallienus (1) pertencentes ao colar ou cinturão (?) procedente dos arredores da cidade síria de Alepo (BRUHN 1993: 34-5 e fig. 29; PERASSI 2004: 908-9, 926, nº. 14, e Fig. 12).

${ }^{6}$ HiERNARD 1979 : 56, assinala que os aurei incluídos nos tesouros terão circulado pouco, antes do seu ocultamento.

A propósito da utilização da moeda de ouro no século III como "valor-refúgio" e a sua imobilização/desmonetização em tesouros, veja-se VEYNE 1979: sobretudo 216-7. Em boa parte, esta prática foi responsável pelas dificuldades financeiras do Estado Romano, já que "il metallo nobile passa dalle casse dello Stato alle tasche dei private", como assinala Lo Cascio (2008: 885).

Conimbriga, 53 (2014) 177-199 
sob os imperadores severos e ainda entre 253 e 275 (Bland 1996: 65). Esta prática ultrapassou mesmo as fronteiras imperiais, como o revelam os estudos deste tipo de achados no limes germanicus, onde a sua presença atinge percentagens muito próximas dentro e fora do Império (HIERNARD 1979: 57). Segundo Vermeule, o florescimento da produção de joias monetárias durante os Severos relaciona-se com a inflação que motivou a acumulação de moeda de ouro e a sua preservação, em que a joalharia desempenhou um papel fundamental. Contudo, entre cerca de 260 e os anos vinte do século seguinte, a produção de joias, utilizando numerário de ouro, torna-se um comércio "quase acidental" que permitia conservar alguns exemplares de um numerário praticamente desaparecido num período de crise e de elevada inflação no território imperial (VERMEULE 1975: 29-30).

$\mathrm{O}$ facto do aureus de Gallienus se encontrar praticamente à florde-cunho indica que foi retirado da circulação não muito tempo após a sua cunhagem, porventura mal chegou às mãos do seu último proprietário. Isto não significa que, de imediato, tenha sido transformado em peça de joalharia, sendo de considerar a probabilidade de ter permanecido guardado durante algum tempo, até ao momento que o seu proprietário tomou a decisão de mandar confecionar o medalhão, mas também não podemos excluir a hipótese da sua aquisição a um ourives/ comerciante de joias já na forma de medalhão. Apesar de tudo, parece verosímil situar-se o fabrico do medalhão algum tempo após a entrada em circulação do aureus, talvez antes do fim do reinado conjunto de Valerianus I e Gallienus (meados de 260) mas poderá também ser posterior, até porque são conhecidos medalhões deste tipo com moedas mais modernas. Brenot e Metzger (1992: 346) referem medalhões com aurei de Valerianus I e II e Victorinus, o que estende a produção de peças deste tipo à década de setenta do século III. Também há registo de guarnições com motivos aparentados, fabricadas para medalhões de solidi nos inícios da segunda metade do século IV, como é o caso de um medalhão com um solidus de Constantius II, pertencente ao achado de Szilágsomlyó (Roménia) (GASDÄC 2007: 15-9, FIG. 4).

$\mathrm{O}$ achado de joias com moedas de ouro engastadas em medalhões ou anéis é extremamente raro na Península Ibérica. Encontrado no século XIX, o anel de Santa Pola (Alicante) com um aureus de Marcus Aurelius, datável entre 163-65 (Brenot \& MetzGer 1992: 335, n. ${ }^{\circ}$ 62 e Bost; CAMPo \& GuRT 1992: 59, $\mathrm{n}^{\circ}$. 145), a servir de mesa, era a única joia monetária romana referenciada para Península Ibérica. O 
medalhão de Tongobriga tem ainda a particularidade de integrar um aureus de Gallienus, também ele muito raro, sendo o quarto exemplar deste imperador recenseado em território hispânico, juntamente com um pertencente ao tesouro da Serra do Condão (Coimbra), achado em 1870 (Bost; CAMPo \& Gurt 1992: 60, nº 155), e dois do já referido achado de Santa Pola (Bost; CAmpo \& Gurt 1992: 59, $\mathrm{n}^{\circ}$. 146). ${ }^{7}$ No entanto, é o único numisma que pertence ao período do reinado conjunto de Valerianus I e Gallienus. Apesar de quase não ter circulado, ou seja, ter cumprido a sua função de moeda, porque foi quase de imediato imobilizado numa joia, não deixa de ser relevante o registo da presença deste aureus no território peninsular, onde a circulação de numerário de ouro durante o século III foi diminuta como o evidenciam diversos estudos (V.g., Sagrede San Eustaquio 1986: 89-98; Huvelin \& Loriot 1992: em especial, 217-42); para a Lusitania, Ruivo 2008: sobretudo, 19-24 e 40-3).

A quantidade de aurei de Gallienus conhecidos, similares ao de Tongobriga é reduzida. Aliás, em termos gerais pode-se dizer que os aurei de Gallienus, assim como os de Valerianus I, cunhados durante o reinado conjunto são bastante raros. Uma pesquisa bibliográfica, em coleções de museus e sobretudo em catálogos de leilões internacionais permitiu coligir 26 exemplares de Gallienus da casa da moeda da Roma, emitidos entre 253-54. Nesta amostra identificaram-se 12 cunhos de anverso com legenda IMPCPLICGALLIENVSAVG - 7 apresentam busto laureado e couraçado à direita $(=\mathrm{C})$ e 5 tem o busto laureado com paludamentum e couraça, vistos detrás $(=\mathrm{PC})$ - e 15 cunhos de reverso (para 11 tipos diferentes), sendo interessantes as ligações de cunhos entre diversos tipos de anverso e reverso, reveladas no quadro que a seguir se apresenta:

\footnotetext{
${ }^{7}$ Por lapso, os autores referem que os dois exemplares apresentavam no anverso a legenda GALLIENVS PF AVG, quando, na verdade, o segundo numisma tem a legenda GALLIENVS AVG, correspondendo ao RIC V/1, 95, enquanto o primeiro deverá identificar-se antes como uma variante de $R I C \mathrm{~V} / 1,94$, como se pode observar nos desenhos publicados por Ramos Folques (1960: Est. XI).
}

Conimbriga, 53 (2014) 177-199 
Aurei Gallienus, 253-254

Peso (g) Cunho Anv. ${ }^{9}$ Cunho Rev.

MIR 36

A) Tongobriga

2,99

C1

IOVICON-SERVA

$25 \mathrm{p}$

B) Ira \& Larry Goldberg Coins

\& Collectibles, Inc., 69, 29.05.2012,3606

= Numismatica Ars Classica $A \mathrm{G}(N A C)$ 62, 06.10.2011, $2069=N A C 31$, 26.10.2005, 98

(S.C. Markoff Collection of Roman Coins)

C) MIR 36, Est. 4.25p

= GÖBL 1978: 1584

D) Heritage Auctions, Inc., 3032, 10.04.2014,

23635 = Christie's, New York, 12.06.1993, 184 (Andre

Constantine Dimitriadis

Collection. Ex McLendon

Collection)

E) $M I R$ 36, Est. 2.15p

= TRAU 1935: 2929

F) Classical Numismatic Group, Triton XVIII,

$06.01 .2015,1220$

G) Staatliche Museen zu Berlin, 18200286

$=$ MIR 36, Est. 3.23p

H) $N A C 67,17.10 .2012,203$

I) Kunsthistorisches Museum, Münzkabinett, Wien 19.406

${ }^{8}$ As fotos aqui reproduzidas são as publicadas pela primeira entidade referida para cada um dos aurei ilustrados (assinalados a negrito).

$9 \mathrm{O}$ algarismo apresentado a seguir às abreviaturas dos tipos de bustos ( $\mathrm{C}$ e $\mathrm{PC}$ ) indicam o número de cunhos detetado para cada um dos tipos. 
J) Roma Numismatics Ltd, IV, 30.09.2012-01.10.2012, 651

K) American Numismatic Society 1967.153.82=MIR 36, Est. 3.22o 3,07

L) Fritz Rudolf Künker $\mathrm{GmbH}$

\& Co. KG, 204,12.03,2012,815 3,25

C3 IOVICONS-ERVA

$25 \mathrm{p}$

M) Hess Divo $A G, 307,07.06 .2007$, 1692 = Adolph Hess AG, Lucerne - Bank Leu AG, Zurich, 41, (Lucerne 1969), 477 et Bank Leu $A G$, Zurich, 48 (1989), $405 \quad 3,09$

N) Numismatik Lanz München, 151, 30.06.2011, 874

O) Cabinet de Médailles (Paris)

$=$ MIR 36, Est. $4.25 \mathrm{o}=$ ALFÖLDI

1967, Est. 31.13

P) Ashmolean Museum (Oxford)

$=$ MIR 36, Est. 5.30o = ALFÖLDI

1967, Est. 31.9

Q) British Museum $=M I R$,

Est. 1.12p

R) Kunsthistorisches Museum,

Münzkabinett, Wien 38.666

$=$ MIR 36, Est. 3.180

S) A. Tkalec $A G$, Auction 07.05.2006, 222

T) $M I R$ 36, Est. 7.38p

= MAZZINI 1957: 1286

U) Fritz Rudolf Künker $\mathrm{GmbH}$ \& Co. KG, 193, 26.09.2011, 982 $=$ Gemini, LLC, VI, 10.01.2010, 561, 10

V) Münzen und Medaillen AG, 19, 5-6.06.1959 = MIR 36, Est. 7.380 
Aurei Gallienus, 253-254

Peso (g) Cunho Anv. Cunho Rev.

MIR 36

X) $M I R$ 36, Est. 4.27o

$=$ TRAU 1935: 2935

- PC

PAX-AVGG

270

W) $M I R$ 36, Est. 8.46p

$=$ MAZZINI 1957: $434=$ ANS

2,85

C6

L-AETITIAAVGG

$46 \mathrm{p}$

Y) Kunsthistorisches Museum,

Münzkabinett, Wien 19.831

$=$ MIR 36, Est. $6.31 \mathrm{p}$

VICTORIAAVGG

$31 \mathrm{p}$

Z) British Museum $=$ MIR 36,

Est. $8.51 \mathrm{p}$

2,77

PR-OVIDENTIAAVGG $51 \mathrm{p}$

É sabido que as casas da moeda não cunhavam moeda de forma contínua, realizando as diversas officinae emissões monetárias em conformidade com necessidades do Estado e de provisão da massa monetária circulante (entre outros autores, veja-se MIR 36: 41 e segs.). Assim, quando se decidia proceder à emissão de numerário, eram definidos os tipos e legendas que iriam ser gravadas nos cunhos para transmitir determinadas mensagens de propaganda, como as virtudes do imperador, as vitórias militares, a proteção das divindades, etc. Na opinião de muitos estudiosos, a eficácia de tais de mensagens seria reduzida porque, para além das dificuldades da maioria dos destinatários para decifrar tal informação, as novas moedas diluir-se-iam rapidamente na massa monetária em circulação composta por material mais antigo, por vezes, com mais de um século de idade (HedLund 2008: 37).

Contudo, no que respeita à moeda de ouro, a situação seria diferente, nomeadamente durante o século III, uma vez que, sendo cunhada em quantidades muito limitadas, se destinava fundamentalmente a “donativa" (Еsтіот 1999: 51 e segs.), isto é, chegaria em primeira mão aos membros da elite civil e militar, próxima do poder imperial e com conhecimentos que permitiriam decifrar mais facilmente as mensagens constantes nas moedas (HEDLUND 2008: 38). A divulgação de certa informação entre as elites seria particularmente sensível neste século de instabilidade, em que a investidura e a manutenção de um imperador no poder muito dependeria dos apoios encontrados nos grupos mais influentes da sociedade civil e do exército. A importância de certas mensagens era relevante nos primeiros momentos de um reinado, em que o imperador procurava consolidar e alargar apoios à sua governação, não

Conimbriga, 53 (2014) 177-199 
surpreendendo que, em todo o reinado de Gallienus (253-268), entre os principais temas representados nos tipos monetários estejam os militares, a associação a divindades e a personificação de virtudes (MANDERS 2012: 271-72).

Pela observação do quadro apresentado das cunhagens de ouro de 253-54 facilmente se constata que os principais temas representados estão em conformidade com o que foi dito anteriormente. Os tipos escolhidos mostram: o deus supremo como protetor (Iuppiter Conservator) do Império (MANDERS 2012: 105-07) e também de Valerianus I e Gallienus (HedLund 2008: 38), que se poderá interpretar com uma legitimação divina dos imperadores; a harmonia (Concordia Exerciti) e a lealdade (Fides Militum) do exército aos imperadores; a personificação de algumas "virtudes" imperiais.

As ligações de cunhos detetadas mostram que cada grupo de cunhagens é oriundo da mesma officina da casa da moeda de Roma, sugerindo também que as primeiras cunhagens de ouro em nome de Gallienus tiveram como principal objetivo comunicar o apoio divino e do exército aos imperadores reinantes. Dentro deste período de 253-54, o conjunto de cunhagens com personificações de virtudes, mas continuando ainda presentes os temas respeitantes a Iuppiter (IOVICONS -ERVA) e ao exército (CONCORDIAMILIT), será o mais tardio.

Em suma, esta rápida análise das cunhagens em ouro do início do reinado conjunto de Gallienus parece indicar que o aureus de Tongobriga deverá incluir-se no grupo das primeiras moedas cunhadas em Roma para Gallienus, por certo, logo após a sua cooptação por Valerianus I, seu pai.

Este medalhão de Tongobriga, com o número de inventário 1227, foi encontrado durante as escavações das termas ${ }^{10}$ na parte exterior do edifício, numa zona localizada nas imediações do antigo balneário castrejo, à cota 308.48 que corresponderá à parte inferior do estrato 7 , uma camada "de aterro com saibro castanho escuro" com uma cronologia posterior a 334/36, contemporâneo dos estratos 4 a 6 (DiAs 1997: 5859 , corte estratigráfico G, H, I (11), (12) da p. 189 e planta desdobrável das termas).

\footnotetext{
${ }^{10}$ Sobre os trabalhos de escavação realizados nas termas romanas e no balneário castrejo, cf. DiAs 1997: 33-64.
}

Conimbriga, 53 (2014) 177-199 
Segundo o responsável pelos trabalhos arqueológicos, a necessidade de elevar a cota neste sector para permitir o acesso ao praefurnium construído no âmbito da transformação de uma antiga sala do edifício em caldarium, está na origem destes aterros (estratos 4 a 7) que foram lançados sobre o estrato 8, cuja parte superior correspondeu ao nível de utilização das termas, desde a sua construção em época flaviana até à sua última remodelação por meados do século IV. Nestes estratos foi exumado material diverso, constituído por fragmentos de sigillata hispânica, cerâmicas comuns romanas, vidro e moedas, com cronologias que se estendem desde o século I ao segundo quartel do século IV (DiAs 1997: 44-59).

Não nos cabendo aqui fazer a interpretação da estratigrafia correspondente a esta zona circundante do edifício termal, devemos destacar, no entanto, que não deixa de ser estranho o aparecimento em camadas de aterro, por exemplo, de um conjunto de 9 moedas (1 antoninianus de Gallienus, 6 de Divus Claudius II e 2 nummi de Constantinus I, datáveis entre 257/9 e 334/6) no estrato 5, à cota 309.46 (DiAs 1997: 57), tornando-se muito difícil explicar o seu agrupamento como ocasional; o mesmo se poderá dizer a propósito do achado do aureus de Gallienus que, para além da sua raridade, era uma peça com demasiado valor para estar integrada em terras de entulhamento, podendo talvez sugerir-se uma contextualização arqueológica distinta da então proposta.

Como se disse atrás, a cota do achado do aureus corresponderá à parte inferior do estrato 7 e, portanto, próxima do nível de utilização das termas até as obras do século IV; por outro lado, neste estrato 7 também foram encontradas mais três moedas -um antoninianus de Tetricus I, de 271/73, e dois nummi constantinianos, de 330/32 e 337/40-, sendo que a mais recente, "muito desgastada", apresenta-se na mesma cota do aureus (DiAs 1997: 58). Pelo que fica dito, a peça de Gallienus terá sido perdida num contexto de utilização das termas, anteriormente à sua derradeira remodelação, que, atendendo ao acentuado desgaste evidenciado pela moeda de 337/40, deverá situar-se seguramente nos inícios da segunda metade do século IV. Esta interpretação ajusta-se, grosso modo, com a(s) cronologia(s) avançada(s) por Lino Tavares Dias para esta fase de obras no edifício, para as quais se apontam duas datas, uma post 357 (DiAs 1997: 42, 48, 55 e 57) e outra post 334/36 (DiAs 1997: $55,57,59$ e 64), fundamentando-se esta última data na leitura da estratigrafia da zona onde apareceu o medalhão de Gallienus (Dias 1997: 55), facto que não é sustentado pela proposta cronológica aqui sugerida para 
este contexto arqueológico. Assim sendo, parece consolidar-se a data mais recente avançada por Lino Dias para a remodelação das termas.

Considerando a data proposta para o fabrico deste medalhão, em torno dos anos cinquenta do século III, constata-se que teve um longo período de uso, talvez durante três gerações, até ter sido perdido cerca de cem anos depois pelo seu derradeiro proprietário, junto ao balneário de Tongobriga, provavelmente um descendente do primeiro dono. Todavia, não sendo conhecidas as circunstâncias em que foi perdido e tratando-se de uma peça com um elevado valor material mas também afetivo, depreende-se que o seu proprietário tudo fez para a recuperar, podendo presumir-se, talvez, a ocorrência de algum acontecimento grave que impediu tal intento e permitiu que o medalhão "visse" a luz do dia cerca de mil e quinhentos anos depois.

\section{BIBLIOGRAFIA}

Abreu, Alberto A. (2006) - Ouro a que a mulher de Viana deu beleza. Viana do Castelo.

ALFÖLDI, Andreas (1967) - Die Haupterreignisse der Jahre 253-261 n. Chr. Im Orient im Spiegel der Münzprägung. In A. Alföldi, Studien zur Geschichte der Weltkrise des 3. Jahrhunderts nach Christus. Darmstadt, p. 123-54 (= Berytus IV-1 1937 41-68).

Bastien, P.; Metzger, C. (1977) - Le trésor de Beaurains (dit d'Arras), (Numismatique Romaine, Essais, Recherches et Documents, X). Wetteren.

Bland, Roger (1996) - The development of gold and silver coin denominations, A.D. 193-253, Studien zu Fundmünzen der Antike 10. Berlim, p. 63-100.

BMCRE VI R.A.G. Carson, Coins of the Roman in the British Museum, Vol. VI: Severus Alexander to Balbinus and Pupienus. Londres, 1962 (reimpr. 2005).

Bost, J.-P.; CAMPO, M.; GuRT, J.M. (1992) - Trouvailles d'aurei et de solidi dans la Péninsule Ibérique. In Brenot, Cl. e Loriot, X. (dir.), L'or monnayé III. Trouvailles de monnaies d'or dans l'occident romain. Actes de la Table Ronde tenue à Paris les 4 et 5 décembre 1987, (Cahiers Ernest-Babelon, 4). Paris, p. 33-89.

Brenot, Cl.; MetzGer, C. (1992) - Trouvailles de bijoux monétaires dans l'occident romain. In Brenot, Cl. e Loriot, X. (dir.), L'or monnayé III. Trouvailles de monnaies d'or dans l'occident romain. Actes de la Table Ronde tenue à Paris les 4 et 5 décembre 1987, (Cahiers Ernest-Babelon, 4). Paris, p. 313-72.

Brunn, A.J. (1993) - Coins and Costume in the Late Antiquity. Washington.

CALlu, Jean-Pierre (1969) - La politique monétaire des empereurs romains de 238 à 311 (Bibliothèque des Écoles Françaises d'Athènes et de Rome, 214). Paris.

CALlu, Jean-Pierre; LoRIOT, Xavier (1990) - L'or monnayé II. La dispersion des aurei en Gaule romaine sous l'Empire, (Cahiers Ernest Babelon 3). Juan-les-Pins.

Conimbriga, 53 (2014) 177-199 
Costa, Amadeu; Freitas Manuel (2011) - Ourar e trajar. Viana do Castelo.

DiAs, Lino Tavares (1997) - Tongobriga. Lisboa.

Estiot, Sylvie (1999) - L'or romaine entre crise et restitution, 270-276 apr. J.-C. I Aurélien, Journal des Savants, Janvier-June, p. 51-147.

GASDÄC, C. (2007) - Zwei Weitere Goldmedaillone aus dem Schatz von Szilágsomlyó (Simleu Silvaniei, Rumänien), Numismatische Zeitschrift 115, p. 15-9.

GöBL, Robert (1951) - Der Aufbau der römischen Münzprägung in der Kaiserzeit, V/1 Valerianus und Gallienus (253-260), Numismatische Zeitschrift 74, p. 8-45.

GöBL, Robert (1953) - Der Aufbau der römischen Münzprägung in der Kaiserzeit, V/2 Gallienus als Alleinherrscher", Numismatische Zeitschrift 75, p. 5-36.

GöBL, Robert (1978) - Antike Numismatik. Munique.

HedLund, Ragnar (2008) - ... achieved nothing worthy of memory. Coinage and authority in the Roman empire c. AD 260-295, (Studia Numismatica Upsaliensica, 5). Uppsala.

HIERNARD, Jean (1979) - L'interprétation des trouvailles d'aurei romains du IIIe siècle: l'exemple des empereurs gallo-romains, Studien zu Fundmünzen der Antike 1. Berlim, p. 39-77.

Huvelin, H.; LoRIOT, X. (1992) - Les trouvailles de monnaies d'or dans l'occident romain au IIIe siècle de notre ère. In Brenot, Cl. e Loriot, X. (dir.), L'or monnayé III. Trouvailles de monnaies d'or dans l'occident romain. Actes de la Table Ronde tenue à Paris les 4 et 5 décembre 1987 (Cahiers Ernest-Babelon 4). Paris, p. 215-72.

Lo CAsCio, Elio (2008) - La dimensione finanziaria e monetaria della crisi del III secolo d.C., Studi Storici 4 (ottobre-dicembre), p. 877-94.

MANDERS, Erika (2012) - Coining images of power: patterns in the representation of Roman emperors on imperial coinage, A.D. 193-284, (Impact of Empire 15). Leiden-Boston.

Marshall, F.H. (1911) - Catalogue of the Jewellery, Greek, Etruscan, and Roman, in the Departments of Antiquities, British Museum. Londres.

MIR 36 - Robert Göbl, MIR (2000) - Moneta Imperii Romani, 36, 43, 44. Die Münzprägung der Kaiser Valerianus I./ Gallienus / Saloninus (253/268), Regalianus (260) und Macrianus / Quietus (260/262), Viena.

Mazzini, G. (1957) - Monete Imperiali Romani. Milão

Perassi, Claudia (2003) - Il pendente aureo con moneta di Salonino dagli scavi dell’Università Cattolica di Milano. In Lusuardi Siena, S. e Rossignani, M. P. (eds.), Dall' Antichità al Medioevo: aspetti insediativi e manufatti. Milano, p. 15-31.

Perassi, Claudia (2004) - Nomismata pro gemmis: pendenti monetali di età romana fra Oriente e Occidente. In Khanoussi, M., Ruggieri, P. e Vismara, C. (eds.), L'Africa Romana. Ai confini dell' Impero: contatti, scambi, conflitti. Atti del XV Convegno di Studio, Tozeur, 11-15 dicembre 2002, Roma, p. 895-932.

Ramos Folques, A. (1960) - Las invasiones germánicas en la provincia de Alicante (siglos III y $V$ de J.C.). Alicante.

Conimbriga, 53 (2014) 177-199 
RIC III - H. Mattingly e E.A. Sydenham, The Roman Imperial Coinage, Vol. III: Antoninus Pius to Commodus. Londres 1930 (reimpr. 1972).

RIC IV/2 - H. Mattingly, E.A. Sydenham e C.H.V. Sutherland, The Roman Imperial Coinage, Vol. IV, Part II: Macrinus Pius to Pupienus. Londres 1938 (reimpr. 1972).

RIC V/1 - P.H. Webb, The Roman Imperial Coinage, Vol. V, Part I: Valerian to Florian. Londres 1927 (reimpr. 1972).

RuIvo, José (2008) - Circulação monetária na Lusitânia do século III, Vol. I, (Dissertação de Doutoramento em Arqueologia, FLUP). Porto.

Sagredo San Eustaquio, L. (1986) - La circulación del áureo en la Hispania del siglo III d. C., Conimbriga 25, p. 89-98.

Trau (1935) - Sammlung Franz Trau. Münzen der römischen Kaiser, Wien.

Vermeule, Cornelius C. (1975) - Numismatics in Antiquity: the Preservation and Display of Coins in Ancient Greece and Rome, Schweizerische Numismatische Rundschau 54, p. 5-32.

VeYne, Paul (1979) - Rome devant la prétendue fuite de l'or : mercantilisme ou politique disciplinaire, Annales. Économies, Sociétés, Civilisations 34 (2), p. 211-44. 


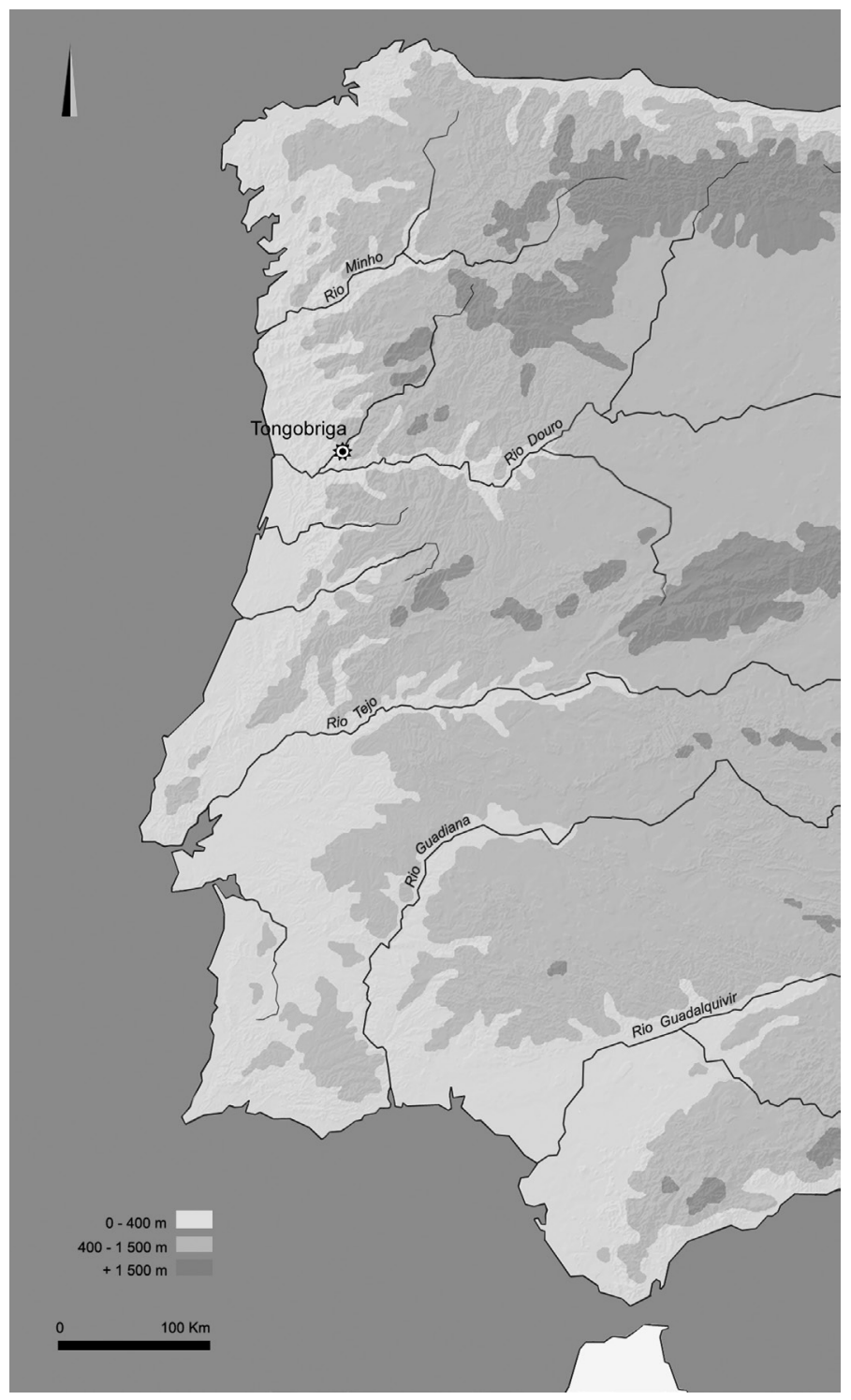

FIG. 1 


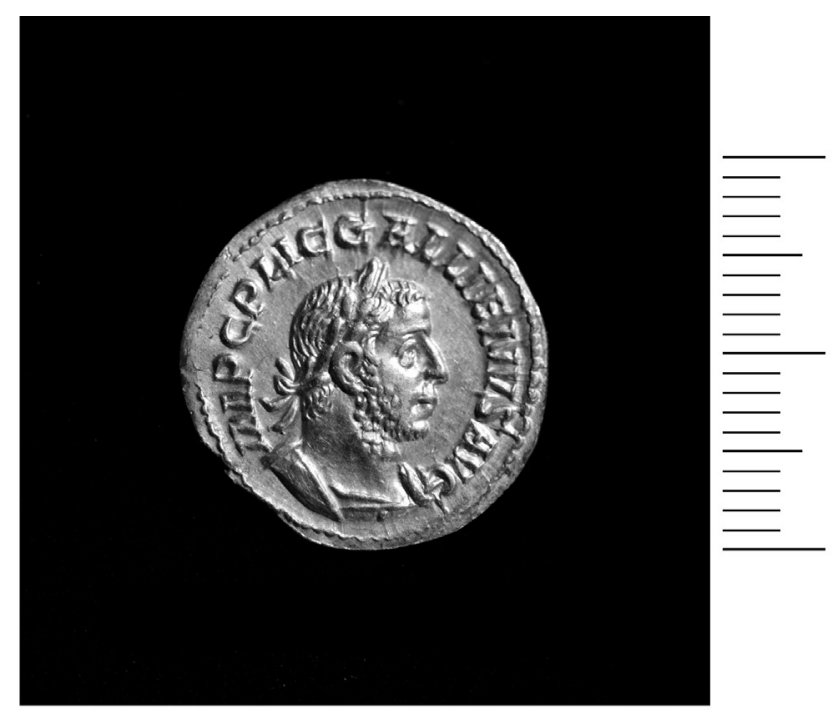

FIG. 2

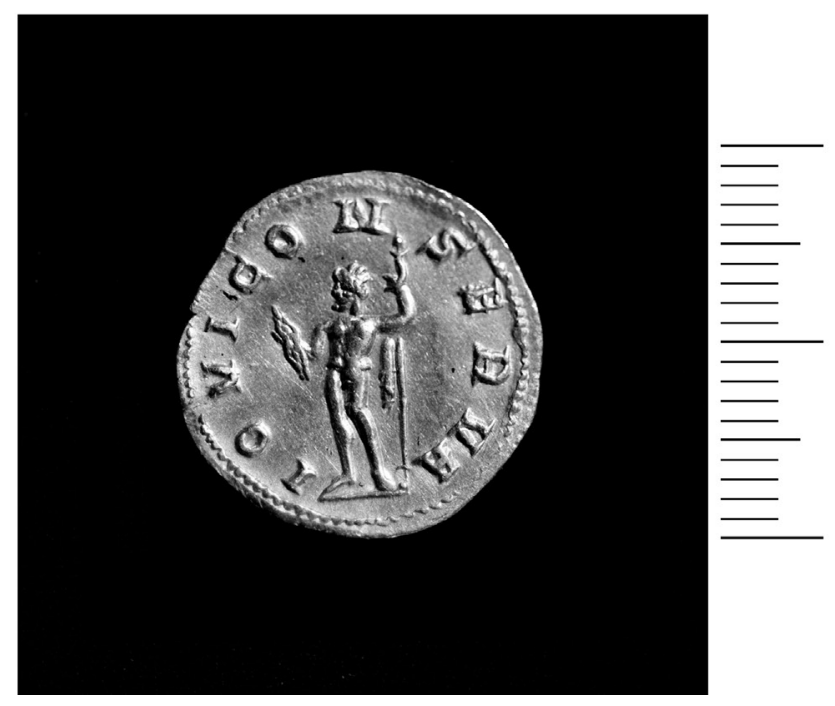

FIG. 3 


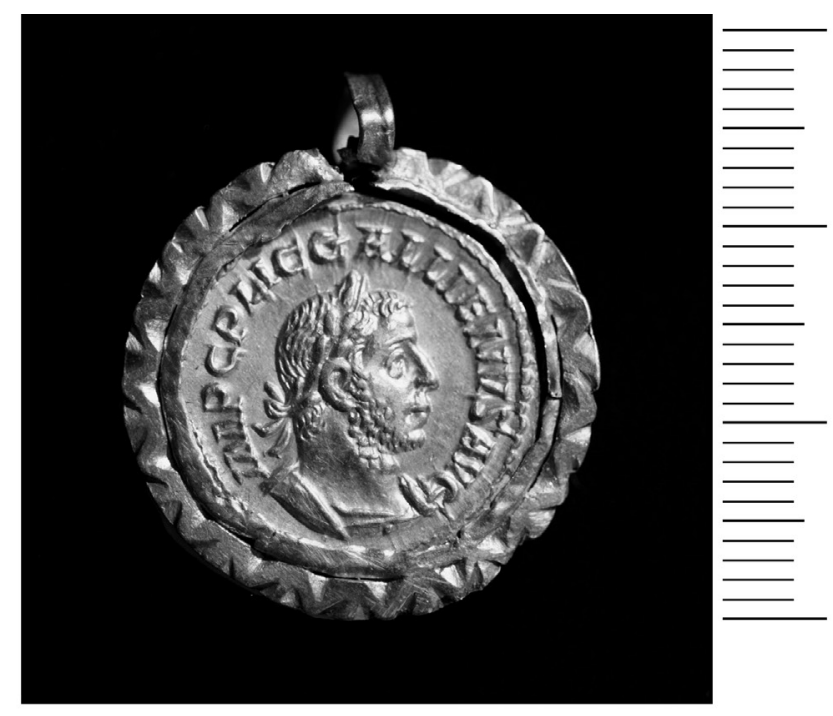

FIG. 4

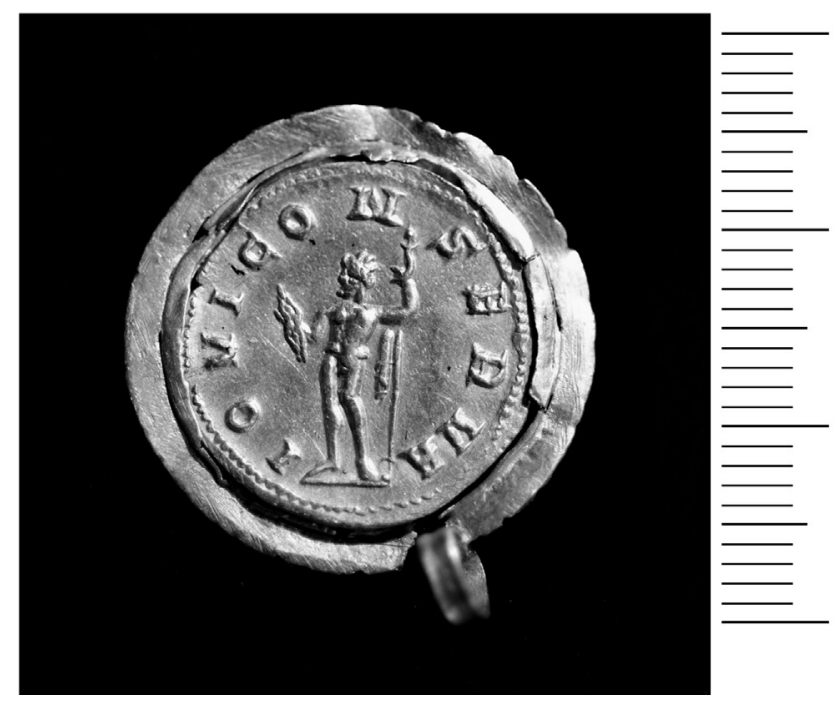

FIG. 5 


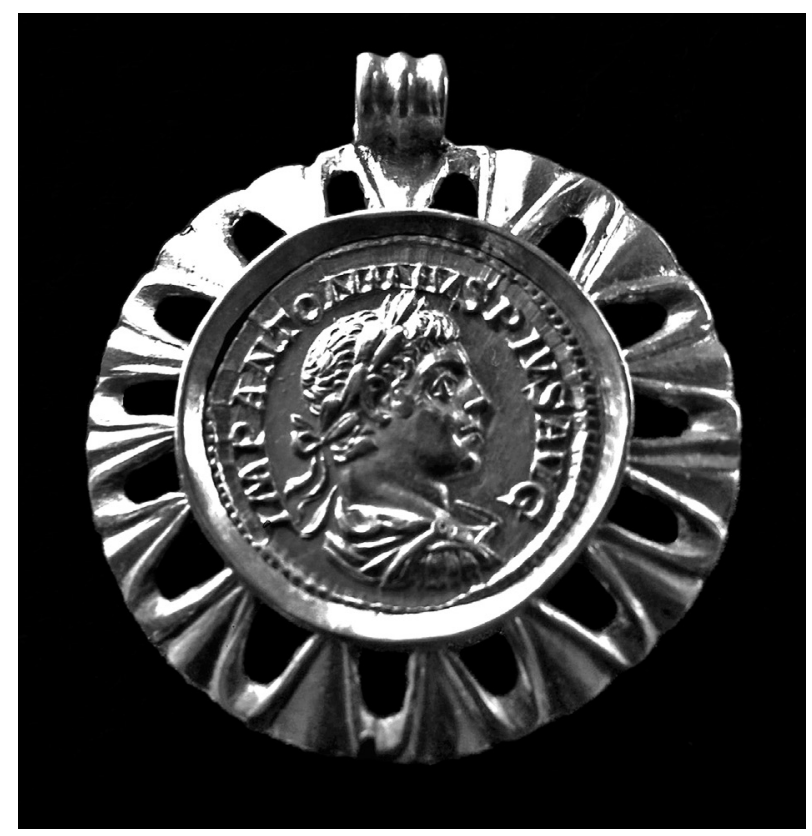

FIG. 6 

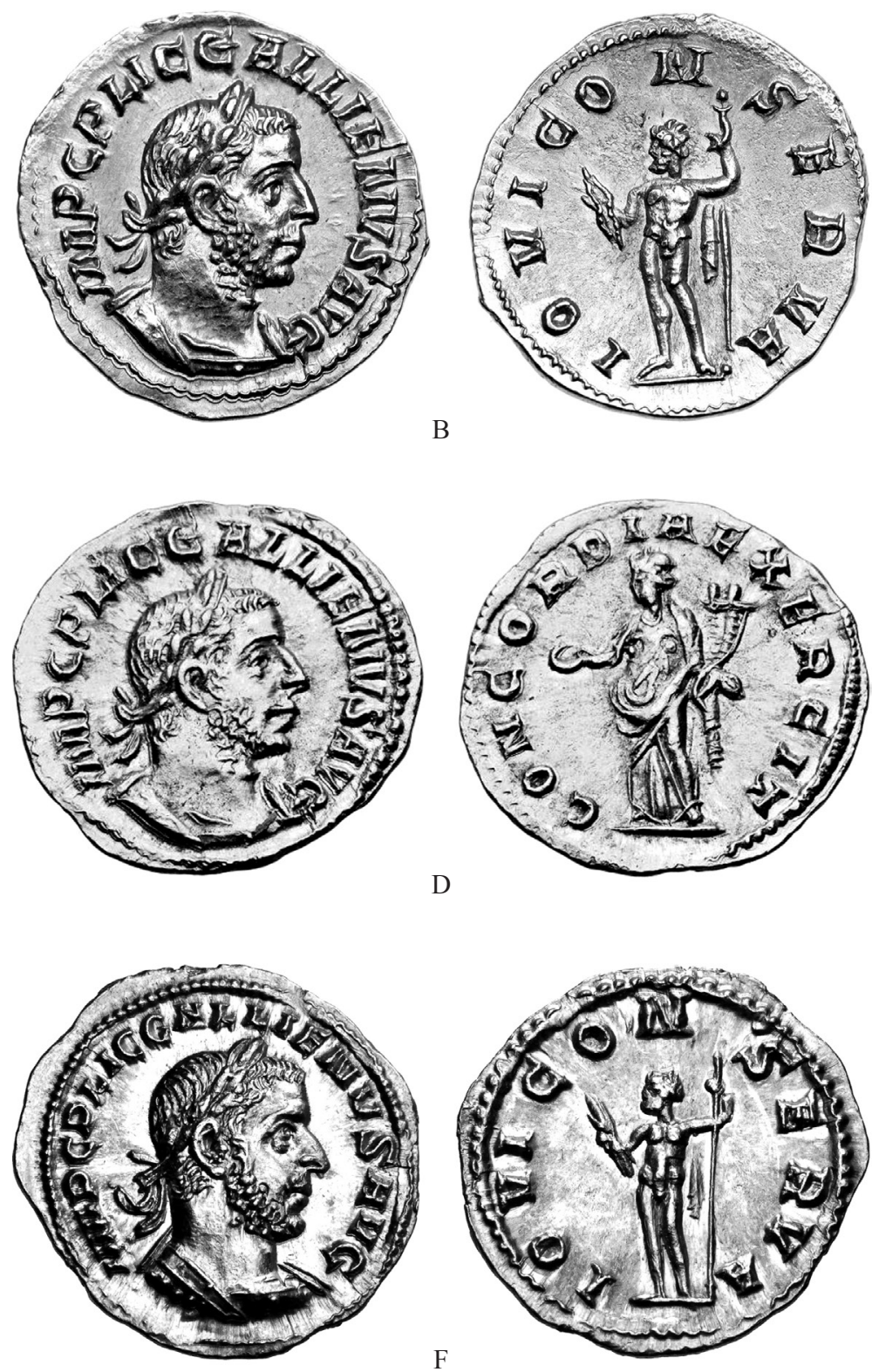

FIG. 7 

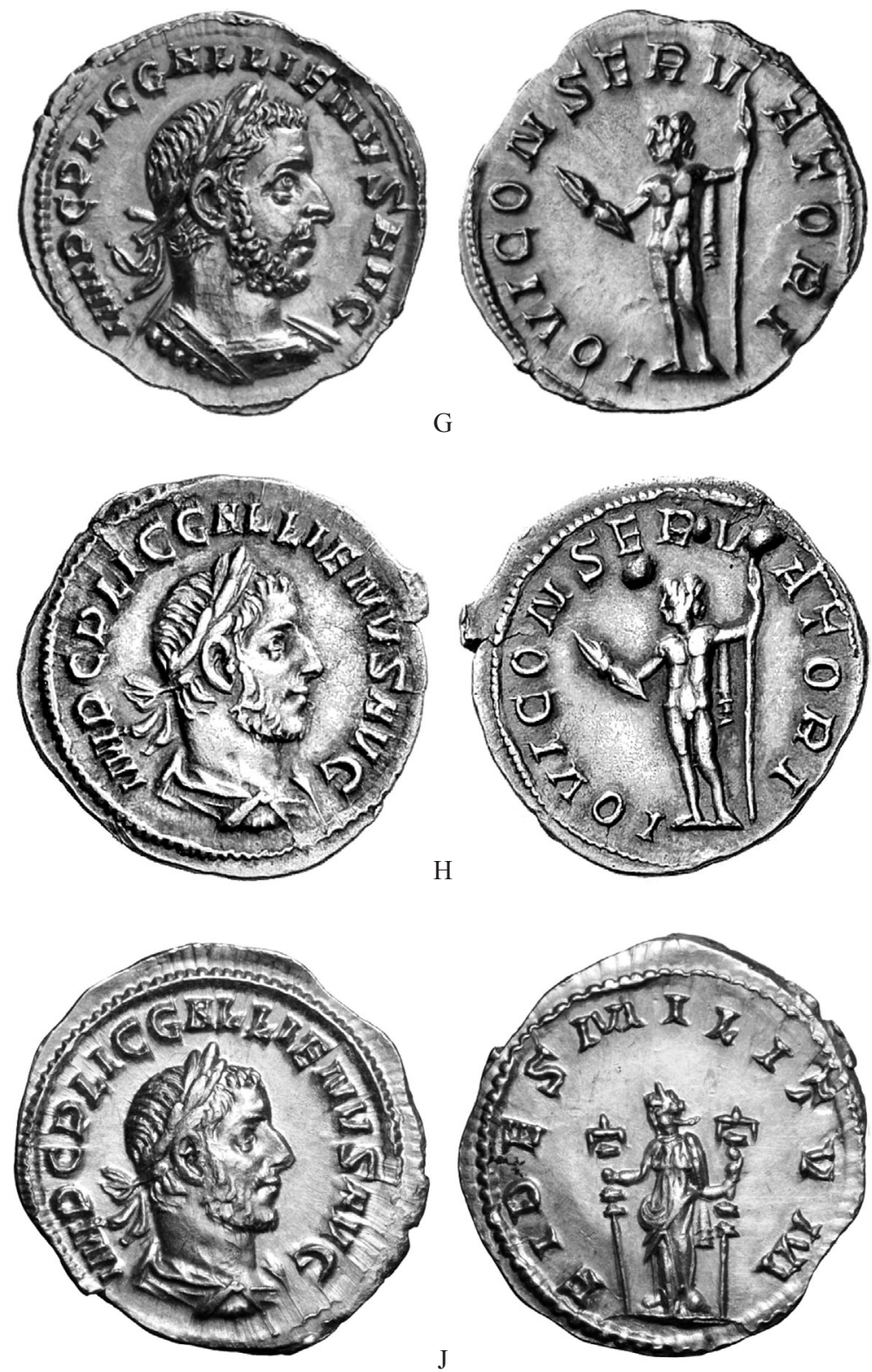

FIG. 8 

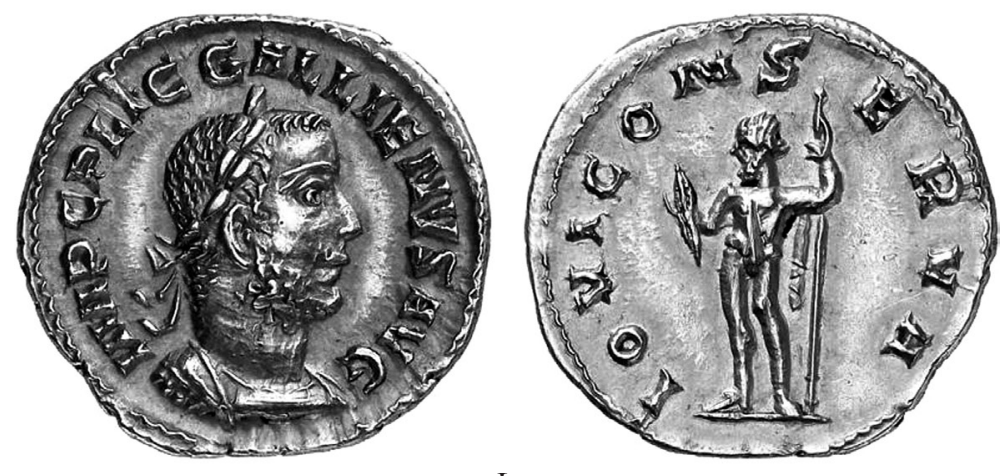

L
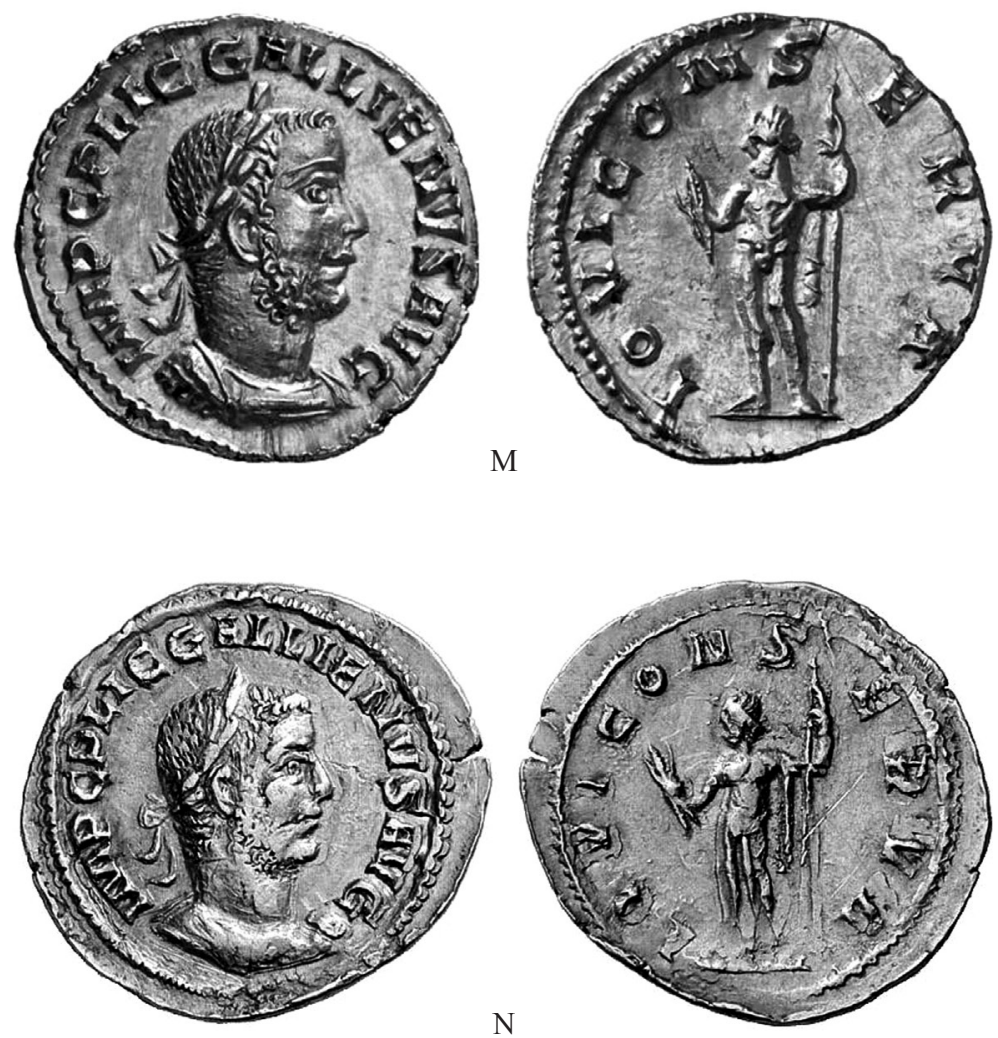

FIG. 9 

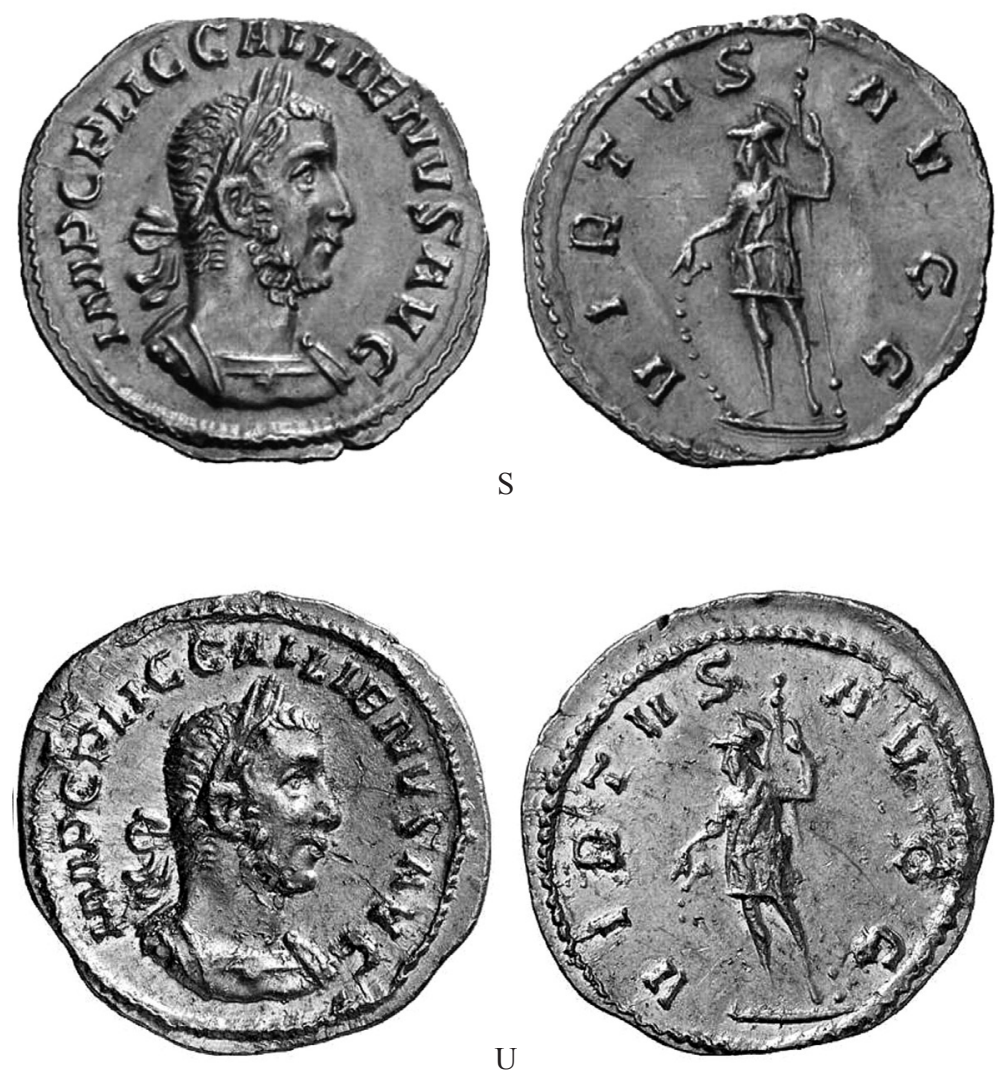

FIG. 10 